\title{
A Rare Case of Diaphragmatic Extralobar Pulmonary Sequestration
}

\section{Francisco Barbosa De Araújo Neto ${ }^{1 *}$, Raphael Gomes Teixeira1, Tiago Castello Branco Lyra1, Glaucio Rodrigo Silva De Siqueira ${ }^{1}$, Stefanie Gallotti Borges Carneiro' ${ }^{1}$, Vinícius Martins Valois ${ }^{1}$, Tiago Bezerra Albano1, Erick Falci Santos', Clóvis Antônio Lopes Pinto², Fábio José Haddad³, Marcos Duarte Guimarães ${ }^{1,2}$}

\author{
${ }^{1}$ Department of Radiology at Hospital Heliópolis, São Paulo, Brazil \\ ${ }^{2}$ Department of Pathology, AC Camargo Cancer Center, São Paulo, Brazil \\ ${ }^{3}$ Department of Thoracic Surgery, AC Camargo Cancer Center, São Paulo, Brazil \\ Email: `Bilbanmaster@gmail.com, Raphagtx@gmail.com, Tiagocbl@hotmail.com, Glauciosiqueira@yahoo.com.br, \\ Marcosduarte500@gmail.com, Stefaniegallotti@hotmail.com,Viniciusmvalois@gmail.com, \\ Tiagob.albano@gmail.com, Erickfalci2@gmail.com
}

How to cite this paper: De Araújo Neto, F.B., Teixeira, R.G., Lyra, T.C.B., De Siqueira, G.R.S., Carneiro, S.G.B., Valois, V.M., Albano, T.B., Santos, E.F., Pinto, C.A.L., Haddad, F.J. and Guimarães, M.D. (2017) A Rare Case of Diaphragmatic Extralobar Pulmonary Sequestration. Open Journal of Medical Imaging, 7, 156-162. https://doi.org/10.4236/ojmi.2017.74015

Received: September 5, 2017

Accepted: October 15, 2017

Published: October 18, 2017

Copyright (๑) 2017 by authors and Scientific Research Publishing Inc. This work is licensed under the Creative Commons Attribution International License (CC BY 4.0).

http://creativecommons.org/licenses/by/4.0/

\begin{abstract}
Context: Bronchopulmonary sequestration is defined as a congenital malformation in which a portion of lung tissue does not communicate with the normal bronchial tree and the pulmonary arteries. Case Report: We present a case of a 35-year-old male complaining of left lower back pain and with a mass in the left thoracoabdominal transition. Imaging studies have suggested a pulmonary sequestration and its diagnosis was confirmed by histopathological study. Conclusion: Diaphragmatic extralobar pulmonary sequestration is a rare anomaly whose radiological diagnosis is difficult. This case is illustrative and demonstrates the importance of imaging methods to the correct diagnosis and effective treatment.
\end{abstract}

\section{Keywords}

Respiratory System Abnormality, Diaphragmatic Pulmonary Sequestration, Extralobar

\section{Introduction}

Pulmonary sequestration is a rare congenital disease, wherein a portion of the lung is non-functional and is not in normal continuity with the tracheobronchial tree, and a blood supply that may derive from systemic vessels. They are encountered in approximately $1 \%-1.8 \%$ of all lung resections [1]. There are two types of pulmonary sequestration: intralobar sequestration and extralobar se- 
questration (intrathoracic and extralobar subdiaphragmatic). Subdiaphragmatic pulmonary sequestration belongs to the extralobar type, and most cases have been reported in association with other congenital malformations. It's not uncommon to be interpreted as an adrenal tumor [2].

Usually, extrathoracic extralobar pulmonary sequestrations are infradiaphragmatic, masquerading as suprarenal masses [3] [4] [5] [6]. Intradiaphragmatic extralobar pulmonary sequestration is rare and there have been very few reported cases until now [7] [8] [9]. The location of extralobar pulmonary sequestrations in the diaphragm sheds light on the relationship between the embryology of sequestration, diaphragm, and lung. The pleuroperitoneal folds form and coalesce the primordial diaphragm from the body wall during the 9th to 12th weeks of gestation; therefore, a bronchopulmonary sequestration that arises during this period may have a higher chance of forming within the diaphragm [8]. True intradiaphragmatic pulmonary sequestrations are rare and all reported cases have been younger than two-year-old. In the present case, atypically, the patient was a 35-year-old male.

We report a rare case of diaphragmatic extralobar pulmonary sequestration, with atypical presentation, once the pulmonary sequestration is subdiaphragmatic, but without others associated malformations. Patients may have different clinical, anatomical and pathological presentations in varying degrees, making this disease present with multiple spectra.

\section{Case Report}

A 35-year-old male patient from the city of São Paulo, SP, sought medical assistance complaining of left lower back pain and asking for a second medical look at a computed tomography (CT) scan from another institution that demonstrated a mass in the left thoracoabdominal transition, of dubious etiology and topography. The patient had a surgical indication for suspected lesion in the left adrenal. We found the same lesion, but we considered it to be of thoracic origin, adjacent to the ipsilateral diaphragm. Video-assisted thoracoscopy and surgical removal of the mass were indicated. During the surgery, the lesion was found to be adhered to the diaphragm, and had to be manually dissected from diaphragmatic fibers.

Chest radiography was performed showing a rounded opacity in the topography of the left lower lobe, in the thoracoabdominal transition (Figure 1(a)). Chest CT and magnetic resonance imaging (MRI) of the abdomen showed an injury in the left thoracic-abdominal transition, indicating it was a mass of adrenal or thoracic origin (Figure 1(b)). The chest MRI confirmed it was an intrathoracic mass, adhered to the diaphragm, in the topography of the left lower lobe (Figure 2(a) and Figure 2(b)). The patient was submitted to resection of the lesion (exploratory laparotomy), which was biopsied and the diagnosis confirmed by histopathological study (Figure 3).

The patient was operated 2 years ago for resection of the lesion (lung 


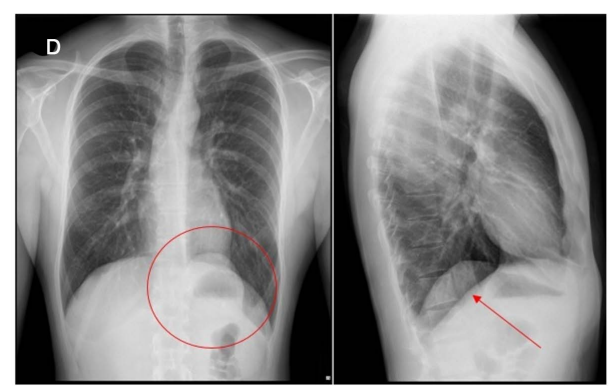

(a)

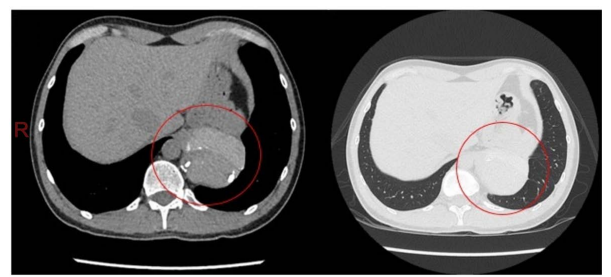

(b)

Figure 1. (a) Chest radiograph (posteroanterior and lateral) showing an opacity in the left thoracoabdominal transition (red circle), between the left inferior lobe and the diaphragm (arrow); (b) Noncontrast chest CT. Soft-tissue window (left) and lung parenchyma window (right) demonstrating a mass with soft-tissue density and with calcifications in the left thoracoabdominal transition (red circles).

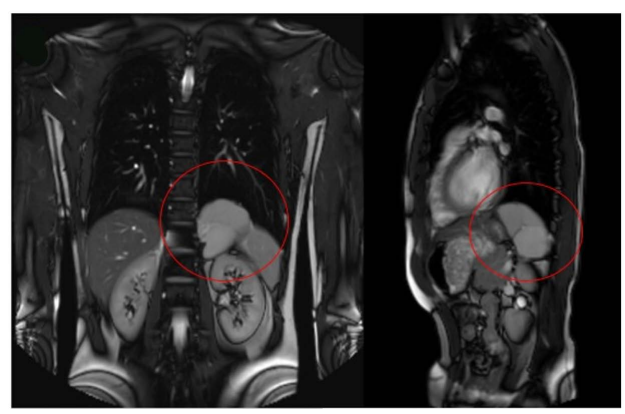

(a)

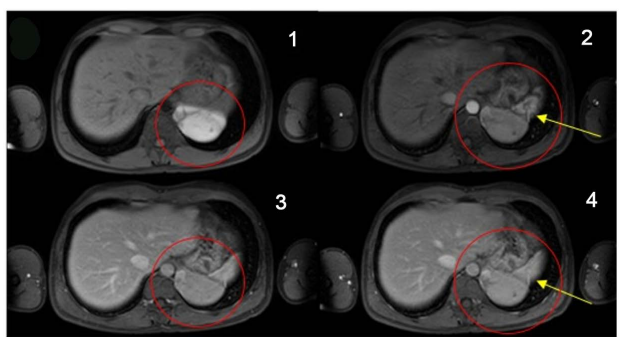

(b)

Figure 2. (a) Magnetic resonance imaging (T2FatSat) of the chest. Coronal (left) and sagittal (right) reconstruction. There is a solid intrathoracic mass with hypersignal (red circle), adjacent to the left diaphragm, in the left thoracoabdominal transition; (b) Magnetic resonance imaging (T1FatSat) of the chest-thoracoabdominal transition-with intravenous infusion of paramagnetic contrast medium. We demonstrated the non-contrast (1), arterial (2), portal (3) and late phases (4). The mass is shown in the left thoracoabdominal transition with hypersignal on $\mathrm{T} 1$ and with heterogeneous contrast enhancement. The mass is probably nourished by a small subphrenic artery (yellow arrow). 


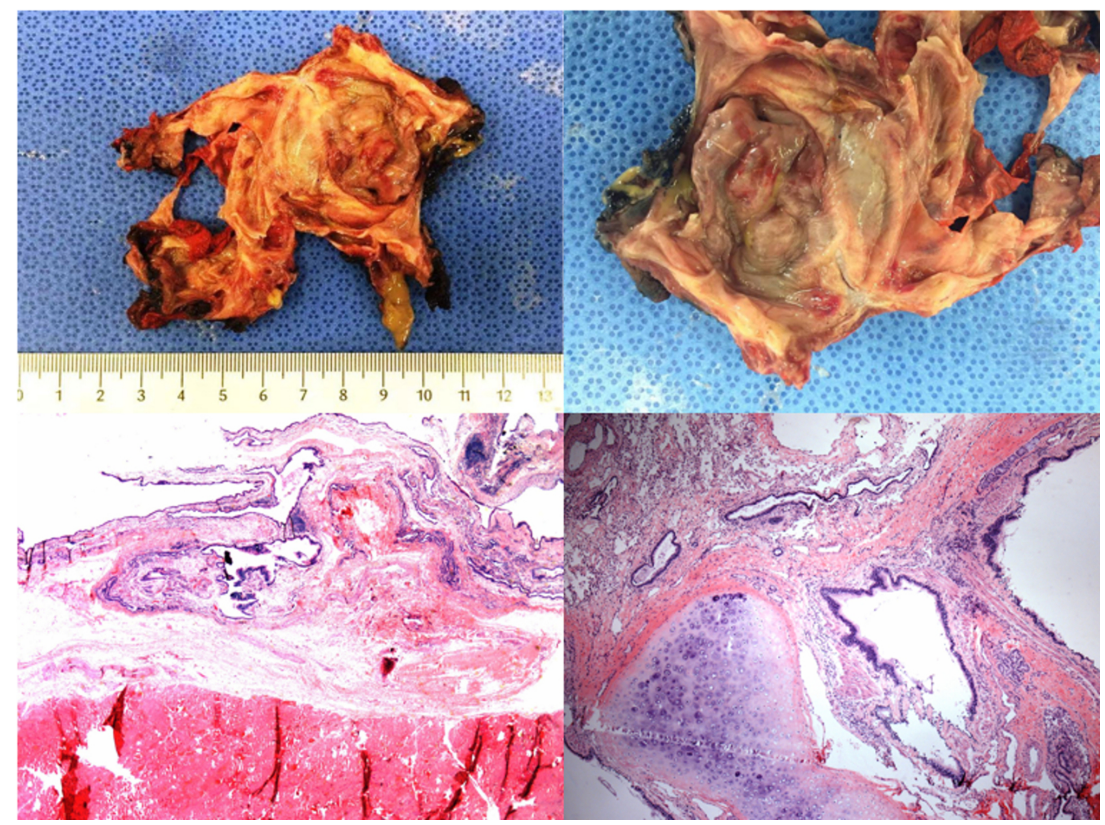

Figure 3. The figures represent the biopsy product after surgical resection of the mass reported in the case. The two upper images represent the macroscopy of the resected lesion. The two lower images represent the microscopic histopathology of the lesion, demonstrating pulmonary tissue within the diaphragmatic tissues.

sequestration) and is being followed clinically. The patient presented no symptoms or no complications so far.

\section{Discussion}

Bronchopulmonary sequestration is defined as a congenital malformation in which a portion of lung tissue does not communicate with the normal bronchial tree, whose blood supply is made by an anomalous systemic artery originating from the aorta or, less frequently, from its branches. The incidence is estimated at $0.1 \%$ [1] [10].

It can be divided into two distinct groups, intralobar and extralobar sequestration, depending on the type of pleural envelopment. Intralobar sequestration accounts for about $75 \%-85 \%$ of all pulmonary sequestration. It has venous drainage through the pulmonary veins, but may occur through other venous systems. It is closely connected to the adjacent normal lung and does not have a separate pleura. It presents later in childhood with recurrent pulmonary infections [11]. Extralobar sequestration accounts for $15 \%-25 \%$ of all pulmonary sequestration. It has venous drainage through the systemic veins into the right atrium, being separated from the adjacent lung and enveloped by its own pleura. Usually present in the neonatal period with respiratory distress, cyanosis and or infection [2]-[12].

Usually, extrathoracic extralobar pulmonary sequestrations are infradiaphragmatic, masquerading as suprarenal masses [3] [4] [5] [6]. Intradiaphragmatic extralobar pulmonary sequestration is rare and there have been very few re- 
ported cases until now [7] [8] [9]. The location of extralobar pulmonary sequestrations in the diaphragm sheds light on the relationship between the embryology of sequestration, diaphragm, and lung. The pleuroperitoneal folds form and coalesce the primordial diaphragm from the body wall during the 9th to 12th weeks of gestation; therefore, a bronchopulmonary sequestration that arises during this period may have a higher chance of forming within the diaphragm [8].

In the radiography, we often detect an opacity in the affected segment, and eventually find cystic spaces when infected [11]. On ultrasonography, the portion of the sequestered lung is generally more echogenic than the rest of the lung. In prenatal ultrasound, an extralobar sequestration can be seen as early as 16 weeks gestation and usually appears as a solid, echogenic, triangular, well-defined mass [13]. On CT, we can see the arterial supply through the descending aorta and the lesions may appear below the diaphragm. Reformations may be particularly useful in the detection of anomalous arterial vessels, anomalous veins and in the differentiation between intralobar and extralobar sequestration [12]. Arteriography allows to characterize well the anomalous arteries and venous drainage, valuable information in the preoperative planning [2]. On MRI, the lesion presents with hypersignal in T1 weighting in relation to the normal lung tissue. OnT2 weighting, it also tends to have a high signal in relation to normal lung tissue [11].

Our case has peculiarities that make it unique. The patient presents a rarity that is the diaphragmatic involvement by the extralobar pulmonary sequestration. Our patient is 35 years old, with the case being atypical, since it is more common in children. Our case is also unique because the patient's symptomatology (left lower back pain) was totally non-specific and unusual for the pathology, presenting no pulmonary complaints. We can summarize the case in Table 1.

Differential diagnoses include diseases such as persistent pneumonia, pulmonary congenital airway malformation (CPAM), bronchogenic and enteric duplication cyst, scimitar syndrome, and congenital diaphragmatic hernia and other less likely differential diagnoses such as neuroblastoma, and adrenal and renal lesions [12].

The treatment is usually surgical, releasing the adjacent pulmonary segment in the extralobar sequestration and frequently having to resect the segments or even to perform a lobectomy in the case of intralobar sequestration [11].

\section{Conclusions}

Diaphragmatic extralobar pulmonary sequestration is a rare and important anomaly whose radiological diagnosis is difficult, most cases being diagnosed during the histopathological study of the resected mass. This case is illustrative and important to be shared with radiologists and the medical community, because of its rarity and atypical presentation. 
Table 1. Reported case of diaphragmatic extralobar pulmonary sequestration.

\begin{tabular}{|c|c|c|c|c|c|}
\hline Age & Sex & Symptom & Imaging studies & Initial diagnosis & Surgical treatment \\
\hline $\begin{array}{c}35 \\
\text { years } \\
\text { old }\end{array}$ & Man & $\begin{array}{l}\text { Left lower } \\
\text { back pain }\end{array}$ & $\begin{array}{l}\text { Chest X-Ray, Computed } \\
\text { Tomography (CT), } \\
\text { Magnetic Resonance } \\
\text { Imaging (MRI) }\end{array}$ & $\begin{array}{l}\text { Mass in the left } \\
\text { thoracoabdominal } \\
\text { transition and Suspected } \\
\text { lesion in the left adrenal }\end{array}$ & $\begin{array}{l}\text { Thoracoscopic } \\
\text { exploration and } \\
\text { Laparoscopic } \\
\text { excision }\end{array}$ \\
\hline
\end{tabular}

This case still demonstrates the difficulty of performing some diagnoses when in the location of cavitary transitions and the importance of imaging methods in medicine, being capable to provide a diagnostic hypothesis for other physicians, allowing correct diagnosis and effective treatment of the patient.

\section{Funding}

No funding was used in this work.

\section{Conflict}

There is no conflict of interest of the authors in this work/document.

\section{References}

[1] Coulier, B., Mailleux, P., Van Cutsem, O., et al. (1999) Diagnosis of Intralobar Pulmonary Sequestration Using Helical Computed Tomography Angiography: Apropos of 3 Patients. Journal Belge de Radiologie-Belgisch Tijdschrift voor Radiologi, 82, 6-10.

[2] Quaglia, M.P. (1995) Congenital Anomalies. In: Pearson, F.G., Ed., Thoracic Surgery, Churchill Livingstone, New York, 411-432.

[3] Kalenahalli, K.V., Garg, N., Goolahally, L.N., et al. (2013) Infradiaphragmatic Extralobar Pulmonary Sequestration: Masquerading as Suprarenal Mass. Journal of Clinical Neonatology, 9, 146-148. https://doi.org/10.4103/2249-4847.120009

[4] Lee, H.C., Cho, K.H., Choi, K.H., Yoon, Y.C., et al. (2009) Retroperitoneal Pulmonary Sequestration in a Neonate. Korean Journal of Thoracic and Cardiovascular Surgery, 9, 364-367.

[5] Hur, J. and Goo, B.W. (2002) Intradiaphragmatic Retroperitoneal Pulmonary Sequestration-A Case Report. Korean Journal of Thoracic and Cardiovascular Surgery, 9, 244-247.

[6] Gross, E., Chen, M.K., Lobe, T.E., et al. (1997) Infradiaphragmatic Extralobar Pulmonary Sequestration Masquerading as an Intra-Abdominal, Suprarenal Mass. Pediatric Surgery International, 9, 529-531. https://doi.org/10.1007/BF01258719

[7] McAteer, J., Stephenson, J., Ricca, R., et al. (2012) Intradiaphragmatic Pulmonary Sequestration: Advantages of the Thoracoscopic Approach. Journal of Pediatric Surgery, 9, 1607-1610. https://doi.org/10.1016/j.jpedsurg.2012.05.010

[8] Nijagal, A., Jelin, E., Feldstein, V.A., et al. (2012) The Diagnosis and Management of Intradiaphragmatic Extralobar Pulmonary Sequestrations: A Report of 4 Cases. Journal of Pediatric Surgery, 9, 1501-1505. https://doi.org/10.1016/j.jpedsurg.2011.11.066

[9] Meier, A.H., Eggli, K.D. and Cilley, R.E. (2009) Intradiaphragmatic Extralobar Sequestration-A Rare Pulmonary Anomaly. Journal of Pediatric Surgery, 9, 27-29. 
https://doi.org/10.1016/j.jpedsurg.2009.09.026

[10] Grigoryants, V., Sargent, S.K. and Shorter, N.A. (2000) Extralobar Pulmonary Sequestration Receiving Its Arterial Supply from the Innominate Artery. Pediatric Radiology, 30, 696-698. https://doi.org/10.1007/s002470000294

[11] Corbett, H.J. and Humphrey, G.M. (2004) Pulmonary Sequestration. Paediatric Respiratory Reviews, 5, 59-68. https://doi.org/10.1016/j.prrv.2003.09.009

[12] Lee, E.Y., Boiselle, P.M. and Cleveland, R.H. (2008) Multidetector CT Evaluation of Congenital Lung Anomalies. Radiology, 247, 632-648.

https://doi.org/10.1148/radiol.2473062124

[13] Dhingsa, R., Coakley, F.V., Albanese, C.T., et al. (2003) Prenatal Sonography and MR Imaging of Pulmonary Sequestration. American Journal of Roentgenology, 180, 433-437. https://doi.org/10.2214/ajr.180.2.1800433 